\title{
Thermodynamics of swelling of latex particles with two monomers: a sensitivity analysis
}

\section{Citation for published version (APA):}

Maxwell, I. A., Noel, E. F. J., Schoonbrood, H. A. S., \& German, A. L. (1993). Thermodynamics of swelling of latex particles with two monomers: a sensitivity analysis. Makromolekulare Chemie, Theory and Simulations, 2(2), 269-274. https://doi.org/10.1002/mats.1993.040020209

DOI:

10.1002/mats.1993.040020209

Document status and date:

Published: 01/01/1993

\section{Document Version:}

Publisher's PDF, also known as Version of Record (includes final page, issue and volume numbers)

\section{Please check the document version of this publication:}

- A submitted manuscript is the version of the article upon submission and before peer-review. There can be important differences between the submitted version and the official published version of record. People interested in the research are advised to contact the author for the final version of the publication, or visit the $\mathrm{DOI}$ to the publisher's website.

- The final author version and the galley proof are versions of the publication after peer review.

- The final published version features the final layout of the paper including the volume, issue and page numbers.

Link to publication

\section{General rights}

Copyright and moral rights for the publications made accessible in the public portal are retained by the authors and/or other copyright owners and it is a condition of accessing publications that users recognise and abide by the legal requirements associated with these rights.

- Users may download and print one copy of any publication from the public portal for the purpose of private study or research.

- You may not further distribute the material or use it for any profit-making activity or commercial gain

- You may freely distribute the URL identifying the publication in the public portal.

If the publication is distributed under the terms of Article 25fa of the Dutch Copyright Act, indicated by the "Taverne" license above, please follow below link for the End User Agreement:

www.tue.nl/taverne

Take down policy

If you believe that this document breaches copyright please contact us at:

openaccess@tue.nl

providing details and we will investigate your claim. 


\title{
Thermodynamics of swelling of latex particles with two monomers: a sensitivity analysis
}

\author{
Ian A. Maxwell*a), Lilian F. J. Noel, Harold A. S. Schoonbrood, \\ Anton L. German \\ Department of Polymer Chemistry and Technology, University of Technology, \\ 5600 MB Eindhoven, The Netherlands
}

(Received: August 20, 1992; revised manuscript of September 14, 1992)

\section{SUMMARY:}

A sensitivity analysis is performed to determine at what conditions the simplified model for swelling of latex particles by two monomers or two solvents is valid. This model proposes that, inter alia, the fractions of two monomers in the latex particles and in the monomer droplets are equal. The model is a simplified version of that proposed by Ugelstad et al. and results from the use of three assumptions, namely (1) the molar volumes of the monomers are equal, (2) the interaction parameters between the two monomers are equal and (3) the interaction parameters between each of the monomers and the polymer are equal. It is shown by simulation that these assumptions are of algebraic necessity only. The simple model is always valid when utilizing realistic values for all the appropriate parameters for partially water soluble monomers that swell the polymer.

\section{Introduction}

Recently, some of us have developed ${ }^{1-3)}$ simplified models for monomer partitioning in emulsion polymer latex systems.

Specifically, these have been developed for the partial swelling of latex particles by one monomer ", the saturation swelling of latex particles by two monomers ${ }^{2)}$ and the partial swelling of latex particles by two monomers ${ }^{3)}$. In this paper we discuss the assumptions utilized in the model for saturation ${ }^{2)}$ and partial ${ }^{3)}$ swelling of latex particles by two miscible monomers and/or solvents, where the monomers or solvents are only partially water soluble and the polymer is soluble in the monomer/solvent mixture. In essence this paper is a sensitivity analysis, performed to determine at what conditions the models previously developed are valid.

\section{Results and discussion}

The equations that fully describe the monomer partitioning of two monomers between the latex particle phase, water phase and (if present) the droplet phase are the cornerstone of the theoretical development of simplified relationships. For monomer $i$ the equations are ${ }^{2-4)}$ : a) Present address: Sydney University Polymer Centre, School of Chemistry, University of
Sydney, NSW 2006, Australia. 


$$
\begin{gathered}
\ln v_{\mathrm{p} i}+\left(1-m_{i j}\right) v_{\mathrm{p} j}+v_{\mathrm{p}}+\chi_{i j} \cdot v_{\mathrm{p} j}^{2}+\chi_{i \mathrm{p}} \cdot v_{\mathrm{p}}^{2}+v_{\mathrm{p} j} \cdot v_{\mathrm{p}} \cdot\left(\chi_{i j}+x_{i \mathrm{p}}-\chi_{j \mathrm{p}} \cdot m_{i j}\right) \\
+\frac{2 V_{\mathrm{m} i} \cdot y v_{\mathrm{p}}^{1 / 3}}{R_{0} \cdot R T}=\ln v_{\mathrm{d} i}+\left(1-m_{i j}\right) v_{\mathrm{d} j}+\chi_{i j} \cdot v_{\mathrm{d} j}^{2}=\ln \left(\frac{\left[\mathrm{M}_{i}\right]_{\mathrm{a}}}{\left[\mathrm{M}_{i}\right]_{\mathrm{a}, \mathrm{sat}}}\right)
\end{gathered}
$$

Similarly, for monomer $j$ it was found ${ }^{\text {a) }}$ :

$$
\begin{gathered}
\operatorname{In} v_{\mathrm{p} j}+\left(1-m_{j i}\right) v_{\mathrm{p} i}+v_{\mathrm{p}}+\chi_{j i} \cdot v_{\mathrm{p} i}^{2}+\chi_{j \mathrm{p}} \cdot v_{\mathrm{p}}^{2}+v_{\mathrm{p} j} \cdot v_{\mathrm{p}} \cdot\left(\chi_{j i}+x_{j \mathrm{p}}-\chi_{i \mathrm{p}} \cdot m_{j i}\right) \\
+\frac{2 V_{\mathrm{m} j} \cdot \gamma v_{\mathrm{p}}^{1 / 3}}{R_{0} \cdot R T}=\ln v_{\mathrm{d} j}+\left(1-m_{j i}\right) v_{\mathrm{d} i}+\chi_{j i} \cdot v_{\mathrm{d} i}^{2}=\ln \left(\frac{\left[\mathrm{M}_{j}\right]_{\mathrm{a}}}{\left[\mathrm{M}_{j}\right]_{\mathrm{a}, \text { sat }}}\right)
\end{gathered}
$$

where $v_{\mathrm{p} i}$ and $v_{\mathrm{p} j}$ are the respective volume fractions of monomer $i$ and $j$ in the latex particles, $v_{\mathrm{p}}$ is the volume fraction of polymer in the latex particles, $\chi_{i j}$ the interaction parameter between monomers $i$ and $j, \chi_{i \mathrm{p}}$ and $\chi_{j \mathrm{p}}$ are the interaction parameters between each of the respective monomers $i$ and $j$ and polymer, $R$ the gas constant, $T$ the temperature, $\gamma$ is the particle-water interfacial tension, $R_{0}$ the unswollen radius of the latex particle, $v_{\mathrm{d} i}$ represents the volume fraction of monomer $i$ in the droplets, $v_{\mathrm{d} j}$ the volume fraction of monomer $j$ in the droplets, $\left[M_{i}\right]_{a}$ and $\left[M_{j}\right]_{a}$ are the concentrations of monomers $i$ and $j$, respectively, in the aqueous phase in the presence of both monomers, and $\left[\mathrm{M}_{i}\right]_{\mathrm{a} \text {, sat }}$ and $\left[\mathrm{M}_{j}\right]_{\mathrm{a} \text {, sat }}$ the saturation concentrations of monomer $i$ and $j$, respectively, in the aqueous phase and in the absence of other monomers. The term $m_{i j}$ is the ratio of the molar volumes of monomers $i$ and $j$ (i.e. $m_{i j}=V_{\mathrm{m} i} / V_{\mathrm{m} j}$, where $V_{\mathrm{m} i}$ and $V_{\mathrm{m} j}$ are the molar volumes of monomer $i$ and $j$, respectively), and the quantity $m_{\mathrm{ji}}\left(=V_{\mathrm{m} j} / V_{\mathrm{m} i}\right)$ is just the reciprocal of $m_{i j}$. Note that the interaction parameter between monomer $j$ and $i$ is given by $\chi_{j i}=\chi_{i j} \cdot m_{j i}$.

The use of Eq. (1.a-b) was considered impractical since the values of many of the parameters contained therein are unknown and difficult to measure ${ }^{2,3)}$. Further, the use of interaction parameters and surface tension that are unchanged by the monomer ratio and volume fraction of polymer within the particle may be a flawed practise $^{2,3,5)}$. In an attempt to overcome these difficulties and also to simplify Eq. $(1 . a-b)$, Maxwell et al. ${ }^{2,3)}$ made the following three assumptions:

Assumption (1): For many pairs of monomer the differences between the molar volumes of the monomers is slight. If this is the case the ratio of the molar volumes of monomer $i$ and $j$ is well approximated by unity, i. e. $m_{i j}=m_{j i}=1$.

Assumption (2): The contribution to the partial molar free energy arising from the residual (enthalpic and non-configurational ${ }^{\text {b) }}$ entropic) partial molar free energy of mixing of the two monomers is small relative to all other terms in the expressions

a) Note that in ref. ${ }^{2)} \chi_{j i}$ was inadvertantly replaced by $\chi_{i j}$ in Eq. (1.b), there numbered (11 b).

b) In the original references ${ }^{1,2)}$ the term 'configurational entropy' was inadvertantly replaced by 'conformational entropy'. This term is also known as combinatorial entropy. 
describing the partial molar free energy of monomers in both the droplet and particle phases (that is, $\chi_{i j}$ is relatively small in the droplet phase and either $\chi_{i j}$ and/or $v_{\mathrm{p}}$ are relatively small in the particle phase).

Assumption (3): The interaction parameters for each monomer with the same polymer are equal $\left(\chi_{i \mathrm{p}}=\chi_{j \mathrm{p}}\right)$.

From these assumptions it was found ${ }^{2)}$ that, inter alia, the monomer volume fractions in the particle phase and droplet phase are equal.

$$
\begin{aligned}
& f_{\mathrm{p} i}=f_{\mathrm{d} i} \\
& f_{\mathrm{p} j}=f_{\mathrm{d} j}
\end{aligned}
$$

where $f_{\mathrm{p} i}, f_{\mathrm{d} i}, f_{\mathrm{p} j}$ and $f_{\mathrm{d} j}$ represent, respectively, the monomer volume fractions of monomers $i$ and $j$ in the droplet and particle phases. Note that in the particle phase these monomer fractions relate only to the volume of one monomer as a fraction of the total volume of both monomers in the particles (i.e. the volume of the polymer in the latex particles is not included in these fractions). Also note that, since we have assumed that the two monomers have equal molar volumes in the derivation of these equations (assumption (1) above), the monomer volume fractions also represent the monomer molar fractions.

Eqs. $(2 . a-b)$ have been shown to hold for a variety of monomer and polymer systems: methyl acrylate-butyl acrylate, methyl acrylate-styrene and butyl acrylatestyrene in various homopolymers and copolymers of the monomer pairs ${ }^{2)}$, methyl acrylate-vinyl acetate in a poly(methyl acrylate-co-vinyl acetate) latex ${ }^{3)}$, and various other systems including styrene-methyl methacrylate in polymer latices with polybutadiene cores and poly(styrene-co-methyl methacrylate) shells ${ }^{6}$ ). The excellent accord between theory and experiment for all these systems has led us to re-examine the three assumptions made to derive Eq. $(2 . a-b)$, in an attempt to establish when it is valid to utilize these results.

\section{Assumption (3)}

In general the theory is only derived for partially water soluble and miscible monomers in which the polymer is soluble. For such systems the interaction parameters between monomer and polymer are usually less than unity (typically ${ }^{7)} \chi_{i \mathrm{p}}=$ $0,1-0,5)$. If assumption (3) is not made, but assumptions (1) and (2) are, then Eq. $(1 . \mathrm{a}-\mathrm{b})$ yield:

$$
\ln \left(\frac{v_{\mathrm{p} i}}{v_{\mathrm{p} j}}\right)-\left(\frac{v_{\mathrm{d} i}}{v_{\mathrm{d} j}}\right)=v_{\mathrm{p}} \cdot\left(\chi_{j \mathrm{p}}-\chi_{i \mathrm{p}}\right)
$$

In Fig. 1 we display the results of numerical solutions to Eq. (3) for various values of the two interaction parameters. Note that these calculations (and all others in this paper) utilize a typical volume fraction of polymer in the latex particles, $v_{p}=0,3$. The solutions to this equation (and all equations in this paper) were found by using the Simplex algorithm ${ }^{8}$ (specifically designed for solving non-linear equations with a 


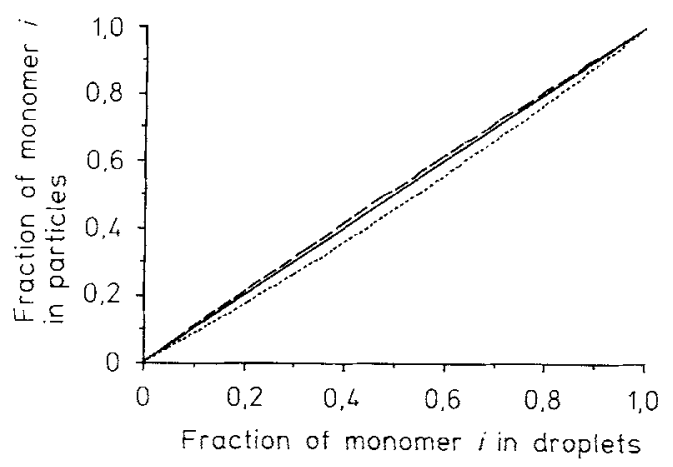

Fig. 1. Monomer mole fraction of monomer $i$ in the latex particles versus monomer mole fraction in the monomer droplets as calculated by Eq. (2) (full line) and Eq. (3) with $v_{\mathrm{p}}=0,3, \chi_{j \mathrm{p}}=0,3$, and $\chi_{i \mathrm{p}}=0,1$ (dashed line) and $\chi_{i \mathrm{p}}=$ 0,9 (dotted line)

unique solution: note that in the present case Eqs. (4) and (5) are non-linear, whereas Eq. (3) is not). In Fig. 1 the point of interest is the small deviation from the most simple result predicted by Eq. (2.a-b). The deviations of Eq. (3) from Eq. (2), with reasonable values for the two interactions parameters, would not be detectable by current experimental techniques (random errors in the method described in refs. ${ }^{2)}$ and ${ }^{3)}$ are approximately $10 \%$; systematic errors cannot be entirely discounted). It is fair to say that, within experimental error, the result predicted by Eq. $(2 . a-b)$ will hold for most systems. The use of Eq. (3) is more correct, but entails the use of two interaction parameters, whose values are difficult to determine. Eq. (3) offers no significant deviation from the simple result of Eq. $(2 \cdot a-b)$.

\section{Assumption (1)}

For two monomers with very different molar volumes it is noted that assumption (1), the approximation that the ratios of the molar volumes of the two monomers are equal, is certainly not valid. For example, the molar volumes of vinyl acetate and vinyl 2-ethylhexanoate are approximately a factor of two different (hence $m_{i j}=0,5, m_{j i}=$ 2). In what follows we test the effect of the inclusion of the ratios, $m_{i j}$ and $m_{j i}$, on the results described by Eq. (2.a-b). Utilizing assumptions (2) and (3), Eq. (1.a-b) yields:

$$
\begin{aligned}
\ln \left(\frac{v_{\mathrm{p} i}}{v_{\mathrm{p} j}}\right)-\ln \left(\frac{v_{\mathrm{d} i}}{v_{\mathrm{d} j}}\right)= & \left(1-m_{i j}\right)\left(v_{\mathrm{d} j}-v_{\mathrm{p} j}-v_{\mathrm{p}} \cdot v_{\mathrm{p} j} \cdot \chi_{i \mathrm{p}}\right) \\
& -\left(1-m_{j j}\right)\left(v_{\mathrm{d} i}-v_{\mathrm{p} i}-v_{\mathrm{p}} \cdot v_{\mathrm{p} i} \cdot \chi_{i \mathrm{p}}\right) \\
& +\frac{2 \gamma v_{\mathrm{p}}^{1 / 3} \cdot\left(V_{\mathrm{m} j}-V_{m i}\right)}{R_{0} \cdot R T}
\end{aligned}
$$

In Fig. 2 the results predicted from Eq. (4) for various values of $m_{i j}$ are displayed. Typical values have been used for all quantities. Once again small deviations are observed from the result predicted by Eq. $(2 . a-b)$. Note that most monomer pairs have values of $m_{i j}$ that deviate from unity by only a small factor; the (normally unrealistic) choices of $m_{i j}=0,5$ and $m_{i j}=0,1$ were chosen to emphasize the effect of these quantities. Eq. (4) can be used at all times in place of Eq. (2.a-b), but it requires 
numerical solution rather than simple equalities, and for most monomer pairs the difference between these two equations is well within observable error.

Fig. 2. Monomer mole fraction of monomer $i$ in the latex particles versus monomer mole fraction in the monomer droplets as calculated by Eq. (2) (full line) and Eq. (4) with $v_{\mathrm{p}}=0,3, \chi_{\mathrm{ip}}=0,3$, temperature $=25^{\circ} \mathrm{C}, R_{0}=100$ $\mathrm{nm}, \gamma=50 \mathrm{dyn} \cdot \mathrm{cm}^{-1}, V_{\mathrm{m} i}=$ $9 \cdot 10^{-5} \mathrm{~m}^{3} \cdot \mathrm{mol}^{-1}$, and $m_{i j}=$ 0,5 (dashed line) and $m_{i j}=0,1$ (dotted line)

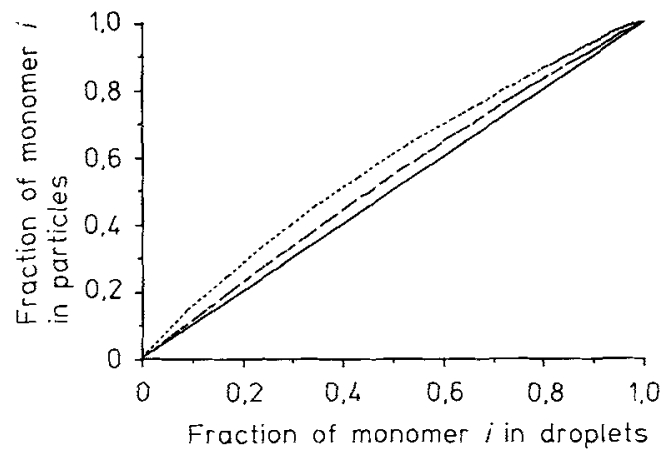

\section{Assumption (2)}

The major assumption in the derivation of Eq. $(2 \cdot a-b)$ from Eq. $(1 . a-b)$ is that the configurational entropy terms dominate over all other terms in Eq. $(1 . \mathrm{a}-\mathrm{b})$. If we accept assumptions (1) and (3) then Eq. $(1 . a-b)$ gives ${ }^{2)}$ :

$$
\ln \left(\frac{v_{\mathrm{p} i}}{v_{\mathrm{p} j}}\right)-\left(\frac{v_{\mathrm{d} i}}{v_{\mathrm{d} j}}\right)=\chi_{i j} \cdot\left[\left(v_{\mathrm{d} j}-v_{\mathrm{d} i}\right)-\left(v_{\mathrm{p} j}-v_{\mathrm{p} i}\right)\right]
$$

Various numerical solutions of Eq. (5) with differing values of $\chi_{i j}$ are displayed in Fig. 3. What is immediately obvious is that larger values of $\chi_{i j}$ result in larger deviation from the simple result of Eq. $(2 . a-b)$. The interaction parameter between two monomers, $\chi_{i j}$, is an unknown quantity, but given the good agreement between experiment and Eq. (2.a-b) for many systems ${ }^{2,3)}$, it is thought that $\chi_{i j}$ is normally less than unity. It is possible that systems exist where this is not the case: these have not been observed in latex systems to date for partially water soluble monomers. Note that the use of assumption (2) states that the configurational entropy of mixing of two monomers is the dominant contribution to the thermodynamic equilibrium reached.

Fig. 3. Monomer mole fraction of monomer $i$ in the latex particles versus monomer mole fraction in the monomer droplets as calculated by Eq. (2) (full line) and Eq. (5) with $v_{\mathrm{p}}=0,3, \chi_{i j}=1$ (dashed line) and $\chi_{i j}=1,5$ (dotted line)

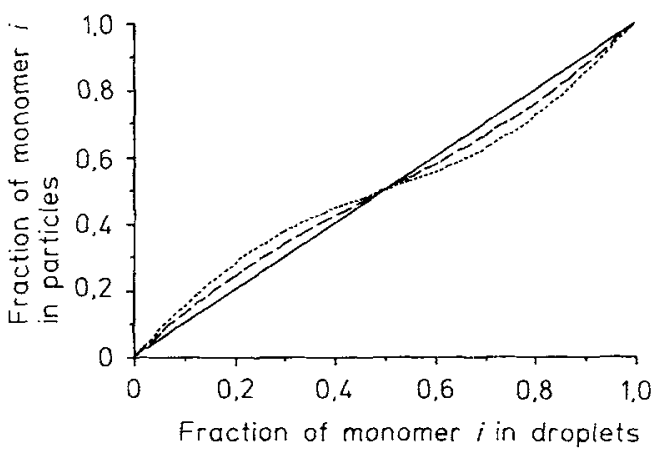


This point is the essence of this thermodynamic treatment: the presence of polymer in the latex particles does not significantly influence the mixing of the two monomers this has been experimentally observed ${ }^{1-3,6}$.

The sensitivity analysis performed in this work can be trivially extended to include, say, the testing of two or three assumptions simultaneously. However, the deviations from the simple results represented by Eq. $(2 \cdot a-b)$ are just superpositions of the numerical results shown for each assumption tested individually, and since they do not describe significant deviations from the test of each assumption individually, for simplicity, they have not been included here.

The conclusions that can be made from this sensitivity analysis are that the three assumptions that allow us to simplify the full equations for two-monomer swelling of latex particles, described by Eq. (1.a-b), to give the simple equations $(2 . a-b)$ (and other results ${ }^{2,33}$ ) are, for typical systems, only of algebraic necessity. The results given by Eq. (2.a-b), for typical values of molar volumes and interaction parameters, are almost always approached by the full equations. The difference between the full and simplified equations is almost always within the random error of current experimental techniques. Hence, the use of the simplified equations can be justified, even if the conditions dictated by the three assumptions are not fully met. The main advantage of the simplified equations is that they do not involve numerical solution by non-linear techniques, nor do they involve the use of interaction parameters, the values of which are difficult to determine by experiment.

1) I. A. Maxwell, J. Kurja, G. H. J. van Doremaele, A. L. German, B. R. Morrison, Makromol. Chem. 193, 2049 (1992)

2) I. A. Maxwell, J. Kurja, G. H. J. van Doremaele, A. J. German, Makromol. Chem. 193, 2065 (1992)

3) L. F. J. Noel, I. A. Maxwell, A. L. German, Macromolecules, submitted

4) J. Ugelstad, P. C. Mork, H. R. Mfutakamba, E. Soleimany, I. Nordhuus, R. Schmid, A. Berge, T. Ellingsen, O. Aune, K. Nustad, in 'Science and Technology of Polymer Colloids"; Vol. 1., G. W. Poehlein, R. H. Ottewill, J. W. Goodwin, Eds., NATO ASI Ser. (1983)

5) P. J. Flory, "Principles of Polymer Sciences", Cornell University Press, Ithaca, New York 1953

6) A. M. Aerdts, M. M. W. A. Boei, A. L. German, Polymer, in press

7) J. Brandrup, E. H. Immergut, "Polymer Handbook"; 2nd edition, Wiley, New York 1975

8) J. A. Nelder, R. Mead, Comput. J. 7, 308 (1965) 